\title{
An Analysis of Influencing Factors in Collaborative Development of the Secondary Industry and the Tertiary Industry in Chengdu, China
}

\author{
Zhigang Liu, Postdoctoral, Associate professor \\ Institue of Economics, School of Humanities \& Social Sciences, Tsinghua University, Beijing 100084, China \\ Yunqing Tan, Postdoctoral, Associate professor \\ School of business and administration, Shanghai Lixin University of Commerce (SLUC), Shanghai 200235, China
}

Caibin Zhu, Lecturer

School of Economics, Beijing Wuzi University, Beijing 101149, China

Received: November 5, 2012

doi:10.5430/rwe.v4n1p35
Accepted: November 19, $2012 \quad$ Online Published: March 7, 2013

URL: http://dx.doi.org/10.5430/rwe.v4n1p35

\begin{abstract}
This paper employs the systematic synergetics model to analyze conditions of collaborative development of the secondary industry and the tertiary industry in Chengdu, China and uses grey correlation method to analyze the primary influencing factors that affect collaboration between the secondary industry and the tertiary industry in Chengdu. Then, taking into consideration of the influencing factors, this paper proposes policies and suggestions to facilitate collaboration between the secondary industry and the tertiary industry so as to better realize rapid and healthy development of economy in Chengdu.
\end{abstract}

Keywords: Collaboration of the secondary industry and the tertiary industry, Degree of systematic collaboration, Grey correlation, Influencing factors

\section{Introduction}

Chengdu takes up an important strategic position in economic development in western areas, especially in Sichuan Province and its occupation of the priority during the transition of economic development directs a direction and offers a template for development of economy in Sichuan Province. It has been discovered from an analysis of the economic structure and industrial structure of Chengdu that, the output value of the secondary industry and the tertiary industry in Chengdu has always been occupying a significant proportion in the entire gross domestic product (GDP). Whether this structure is reasonable and collaborative is the foundation for economic transition and adjustment of the industrial structure. Establishment of the model of collaboration degree of the secondary industry and the tertiary industry in Sichuan Province helps to measure collaboration between the secondary industry and the tertiary industry. According to the result of measurement, this paper analyzes the influencing factors that affect collaborative development of the secondary industry and the tertiary industry. Furthermore, on that basis, the paper puts forward pertinent suggestions to better facilitate collaboration between the two industries in Chengdu so as to make the industrial structure more reasonable and the economic development more healthy and orderly.

\section{Literature Review}

In the past few years, with the rapid development of the national economy, emphasis of the governments at all levels on the adjustment of the industrial structure and the transition of economic developmental patterns and industrial collaboration as well as adjustment of industrial structure, etc., gradually become the much-talked-about topics in the academic research field. Nevertheless, most of current studies on industrial collaboration focus on discussion of the property, but have not formed a complete and scientific research system. Most of the studies of industrial collaboration have been gradually introduced from coordination of industrial structure. Among the foreign academics, the German Physicist Herman Haken was the first who concentrated on industrial collaboration. Haken (1971-1983) published successively "Introduction to Synergetics" and "Advanced Synergetics" with his students and initiated the pioneering work in study on industrial collaboration. Afterwards, more and more academics began to participate in 
study on industrial collaboration. Chinese domestic scholars also have conducted studies on collaboration of the three industries from the perspectives of change of industrial structure (Liu Wei and Li Shaorong, 2002), industrial organization (Yang Jirui, 2003), industrial chain (Li Qinlin, 2004), regional space (An Husen, 2005) and so on. In addition, Zhao Xinhua (2009), An Shiyin (2007), Dong Chun (2008) et al have successively conducted relevant studies on industrial collaboration. Nonetheless, a general survey at the current studies, it is found that there have been relatively a large number of qualitative studies and relatively a small number of quantitative studies, relatively much theoretical analysis and little empirical analysis. The study in this article employs the industrial data in Chengdu by establishing the model of degree of industrial collaboration and makes an empirical analysis that the development conditions of the secondary industry and the tertiary industry in Chengdu can, to some extent, make up for disadvantages of the current studies, and, in the mean time, provide a new research method and train of thought for study on industrial collaboration, which offers reference for studies on follow-up industrial collaboration.

\section{Establishment of Indicator System and Source of Data}

\subsection{Establishment of Indicator System}

Measurement of the degree of industrial collaboration needs to establish a certain evaluation indicator system. After reviewing the present studies, this article establishes an indicator system for collaboration of the secondary industry and the tertiary industry according to reality of the study issues, which is shown as in Table 1.

$<$ Insert Table 1 Here $>$

\subsection{Source of Data}

Data in this article mainly originate from the statistical bulletin of Chengdu in 2009 and the statistical yearbook in 2010. In the mean time, for convenience of handling the problems, we conducted relevant processing to the initial data in specific using of the data, including totaling, comparison and so on.

\section{Measurement of Degree of Collaboration between the Secondary Industry and the Tertiary Industry in Chengdu}

4.1 Establishment of the Systematic Collaboration Degree Model of Collaboration between the Secondary Industry and the Tertiary Industry

4.1.1 Order Degree Model of the Secondary Industry and the Tertiary Industry

Supposing that the order parameter in the developmental process of the system of the secondary industry is e $1=(\mathrm{e} 11$, $12, \ldots, \mathrm{e} 1 \mathrm{n})$, where $\mathrm{n} \geq 1, \beta 1 \mathrm{i} \leq \mathrm{e} 1 \mathrm{i} \leq \alpha 1 \mathrm{i}, \mathrm{i} \in[1, \mathrm{n}]$. In the study of this article, the order parameter variable of the system of the secondary industry can be seen as the evaluation indicator of the secondary industry. Without loss of generality, assuming that $\mathrm{e} 11,12, \ldots, \mathrm{e} 1 \mathrm{j}$ is the slow transition parameter, then the larger its value, the higher the degree of order of the system, and the smaller its value, the lower the degree of order of the system. And assuming that $\mathrm{e} 1 \mathrm{j}+1,1 \mathrm{j}+2, \ldots, \mathrm{e} 1 \mathrm{n}$ is the fast transition parameter, then the larger its value, the lower the degree of order of the system, and the smaller its value, the higher the degree of order of the system. Hence, we get the following definition.

Definition 1: the following formula stands for the degree of order of the system of the component eli of the systematic order parameter of the secondary industry:

$$
u_{1}\left(e_{1 i}\right)=\left\{\begin{array}{l}
\frac{e_{1 i}-\beta_{1 i}}{\alpha_{1 i}-\beta_{q i}}, i \in[1, j] \\
\frac{\alpha_{1 i}-e_{1 i}}{\alpha_{1 i}-\beta_{1 i}}, i \in[j+1, n]
\end{array}\right.
$$

It can be known from the above definition that $\mathrm{u} 1(\mathrm{e} 1 \mathrm{j}) \in[1, \mathrm{n}]$. The larger its value, the larger the "contribution" of eli to order of the system of the secondary industry. Here, it is necessary to point out that, in reality, it is not feasible that the value of eli is too large or too small, and it is better to concentrate its value around a particular scope. As for such kind of eli, we can always make the definition of its degree of order meet with Definition 1 by means of adjusting its interval of value $[\beta 1 \mathrm{i}, \alpha 1 \mathrm{i}]$. Generally speaking, the "total contribution" of the order parameter variable eli to the order degree of the system of the secondary industry can be fulfilled through integration of u1(e1i). 
However, the method of "integration" depends on the different combination patterns of specific structure of the system. For consideration of conciseness, this article employs the geometric method to deal with it:

$$
u_{1}\left(e_{1}\right)=\sqrt[n]{\prod_{j=1}^{n} u_{1}\left(e_{1 j}\right)}
$$

Definition 2: we term u1(e1) in the above formula as the order degree of the system of the secondary industry.

It can be known from Definition 2 that $\mathrm{u} 1(\mathrm{e} 1) \in[0,1]$. The larger the value of u1(e1), the larger the "contribution" of e1 to the order of the system of the secondary industry and the higher the order degree of the system, whereas lower.

\subsubsection{Order Degree Model of the System of the Tertiary Industry}

Similar to assumption of the order degree model of the secondary industry system, likewise, we can get the following definitions:

Definition 3: the following formula stands for the systematic order degree of the order parameter component e2i of the tertiary industry:

$$
u_{2}\left(e_{2 i}\right)=\left\{\begin{array}{l}
\frac{e_{2 i}-\beta_{2 i}}{\alpha_{2 i}-\beta_{2 i}}, i \in[1, j] \\
\frac{\alpha_{2 i}-e_{2 i}}{\alpha_{2 i}-\beta_{2 i}}, i \in[j+1, n]
\end{array}\right.
$$

Definition 4: we term u2(e2) that is defined in the following formula as the systematic order degree of the tertiary industry:

$$
u_{2}\left(e_{2}\right)=\sqrt[n]{\prod_{j=1}^{n} u_{2}\left(e_{2 j}\right)}
$$

It can be known from Definition 4 that u2(e2) $\in[0,1]$. The larger the value of u2(e2), the larger the "contribution" of e2 to the order of the system of the tertiary industry and the higher the order degree of the system, whereas lower.

\subsubsection{Collaboration Degree Model of the System of the Secondary Industry and the Tertiary Industry}

Collaboration degree of the system of the secondary industry and the tertiary industry refers to the degree of harmony and consistency of the system of the secondary industry and the system of the tertiary industry in the process of their respective development and evolution through interaction, which determines the tendency and degree of the process in which the system of the secondary industry and the tertiary industry goes from disorder to order.

Supposing that at the initial time (or a certain particular time slot) of t0, the order degree of the system of the secondary industry is u10(e1) and the order degree of the system of the tertiary industry is u20(e2), whereas at the moment of $\mathrm{t} 1$ in the process of evolution of the entire system of the secondary industry and the tertiary industry, the order degree of the system of the secondary industry is $\mathrm{u} 11(\mathrm{e} 1)$ and the order degree of the system of the tertiary industry is u21(e2).

Definition 5: the following formula is the collaboration degree of the subsystem within the system of the secondary industry and the tertiary industry:

$$
C=\lambda \cdot \sqrt{\left|u_{1}^{1}\left(e_{1}\right)-u_{1}^{0}\left(e_{1}\right)\right| \times\left|u_{2}^{1}\left(e_{2}\right)-u_{2}^{0}\left(e_{2}\right)\right|}
$$

Where,

$$
\lambda=\left\{\begin{array}{l}
1, \quad\left[u_{1}^{1}\left(e_{1}\right)-u_{1}^{0}\left(e_{1}\right)\right] \times\left[u_{2}^{1}\left(e_{2}\right)-u_{2}^{0}\left(e_{2}\right)\right]>0 \\
1, \quad\left[u_{1}^{1}\left(e_{1}\right)-u_{1}^{0}\left(e_{1}\right)\right] \times\left[u_{2}^{1}\left(e_{2}\right)-u_{2}^{0}\left(e_{2}\right)\right] \leq 0
\end{array}\right.
$$


Illustration to Definition 5:

In the first place, $C \in[-1,1]$, the larger its value, the higher the degree of the coordinated development of the entire system of the secondary industry and the tertiary industry, whereas lower.

In the second place, function of the parameter $\lambda$ lies in that it judges the direction of coordination between the subsystem of the secondary industry and the subsystem of the tertiary industry. When $[\mathrm{u} 11(\mathrm{e} 1)-\mathrm{u} 10(\mathrm{e} 1)] \times[\mathrm{u} 21(\mathrm{e} 2)-\mathrm{u} 20(\mathrm{e} 2)]>0$, the coordination degree $\mathrm{C}$ is manifested as development of the two subsystems in the same direction and the larger the value of $\mathrm{C}$, the higher the degree of coordination. When $[\mathrm{u} 11(\mathrm{e} 1)-\mathrm{u} 10(\mathrm{e} 1)] \times[\mathrm{u} 21(\mathrm{e} 2)-\mathrm{u} 20(\mathrm{e} 2)] \leq 0$, the coordination degree $\mathrm{C}$ is manifested as development of the two subsystems in opposite directions or out of tune. And the smaller the value of $\mathrm{C}$, the lower the degree of coordination.

In the third place, definition 5 has taken an overall consideration of the two subsystems. If the order degree of one of the two subsystems is increased to a large extent and the order degree of the other subsystem is increased to a small extent, then the entire system is unlikely to be in perfect coordination. In addition, as for the entire system, a general mastery of the coordination condition of the whole industrial system in the process of changes of the order degree of the subsystem is a kind of dynamic analysis.

\subsection{Measurement of Collaboration Degree of the Secondary Industry and the Tertiary Industry}

\subsubsection{Nondimensionalization Processing of Data}

Since there are quite a large number of indicators and the units of the indicators are not identical, it is necessary to conduct the nondimensionalization processing on the data for convenience of the processing so as to make different indicators and data with different units nondimensionalized. The formula of nondimensionalization is as below:

$$
S_{i}=e_{j i}-\overline{e_{j i}} / \sigma_{i}(J=1,2 ; i=1,2,3 \cdots, n)
$$

Where, $\overline{e_{j i}}$ is the mean value and $\sigma_{i}$ is the standard deviation.

\subsubsection{Degree of Order}

According to the indicator system, we substituted the data of the statistical yearbook and the data of the statistical bulletin of Chengdu from 2004 to 2010 and got the following order parameter, with the result of calculation in Table 2:

$<$ Insert Table 2 Here $>$

Meanwhile, with data in the above table, we get the icons of the total degree of order of the secondary industry and the tertiary industry, which is shown in Figure 1 and Figure 2.

$<$ Insert Figure 1 and Figure 2 Here $>$

\subsubsection{Systematic Collaboration Degree}

According to data of the degree of order got in Section 4.2.2, we substituted the data into the systematic collaboration degree model and got the collaboration degree of the secondary industry and the tertiary industry in Sichuan Province, as is shown in the following Figure 3.

$<$ Insert Figure 3 Here $>$

\section{An analysis of the Influencing Factors in Collaboration of the Secondary Industry and the Tertiary Industry in Chengdu}

\subsection{Usage of the Analysis Method}

Grey correlation analysis method is an overall evaluation method, which was initiated for the first time by Professor Deng Julong, a domestic scholar, in the 80s of the Twentieth Century. Grey correlation analysis method is widely applied and has obvious disadvantages in analysis of the influencing factors and measurement of complex systems. This method uses relatively a small number of data and is able to realize a specific analysis of abstract problems. At the same time, it is able to find out the ordering relation of influencing factors of collaboration of the secondary industry and the tertiary industry and find out the focus and attention and methods for resolving the problems. 


\subsection{Grey Correlation Analysis of the Secondary Industry and the Tertiary Industry in Chengdu}

\subsubsection{Nondimensionalization Processing of the Initial Data}

Since there are quite a lot of choices for indicators and the units of the indicators are not identical, nondimensionalization processing of the initial data is necessary in grey correlation analysis. We mainly employ the initialization method as the processing method for processing of the initial data. The detailed process is as below:

supposing that $X_{0}(t)$ is the parent sequence and $\mathrm{X}_{\mathrm{i}}(t)$ is the sub-sequence. Then, nondimensionalization processing is made respectively on $X_{0}(t)$ and $\mathrm{X}_{\mathrm{i}}(t)$, and their absolute value $\Delta_{0 i}(t)=\left|x_{0}(t)-x_{i}(t)\right|,(i=1,2, \cdots n)$ is recorded at the moment of $t$. We get the initial value as is shown in Table 3 and the difference value as is shown in Table 4.

$<$ Insert Table 3 and Table 4 Here $>$

\subsubsection{Calculation of Correlation Coefficient}

The following formula is termed as the correlation coefficient of the sequence $x_{0}(t)$ and sequence $x_{i}(t)$ at the moment of $\mathrm{k}$.

$$
\xi_{i}(k)=\frac{\min _{i} \min _{k}\left|x_{0}(k)-x_{i}(k)\right|+0.5 \max _{i} \max _{k}\left|x_{0}(k)-x_{i}(k)\right|}{\left|x_{0}(k)-x_{i}(k)\right|+0.5 \max _{i} \max _{k}\left|x_{0}(k)-x_{i}(k)\right|}
$$

In the above formula, 0.5 is the discrimination coefficient, which is marked as $\xi$ and which is usually selected between the value 0 and 1 . We got the difference value in Table 4 after calculation. Then, we got the maximum difference $\max _{i} \max _{k}\left|x_{0}(k)-x_{i}(k)\right|$ and the minimum difference $\min _{i} \min _{k}\left|x_{0}(k)-x_{i}(k)\right|$ from Table 4 and we substituted the maximum value and the minimum value into the above formula and got the following Table 5 .

$<$ Insert Table 5 Here $>$

\subsection{Result of Grey Correlation Analysis and Analysis of the Reasons}

\subsubsection{Result of Grey Correlation Analysis}

We substituted the correlation coefficient in Table 5 into the formula of relevancy $r_{i}=\frac{1}{N} \sum_{k=1}^{N} \xi_{i}(k)$ and got the result as is shown in the following Table 6:

$<$ Insert Table 6 Here>

It can be seen from the above table that, according to the importance of influencing factors that affect collaboration of the secondary industry and the tertiary industry in Chengdu, the sequencing of these influencing factors are successively industrial value added, value added of the construction industry, traffic and transportation, and so on. Among all the influencing factors, industrial value added has the biggest influence and its relevancy coefficient is 0.924788 , and the second one is the construction industry, with a relevancy coefficient of 0.924007 . It is investment of fixed capital in the secondary industry that has the smallest influence whose relevancy coefficient is 0.540162 .

\subsubsection{Analysis of Reasons}

The above analysis result has definite reasons. Firstly, the driving force of industrial value added on economic development in Chengdu, especially industrial collaboration, is extremely obvious. However, investment of fixed capital is no longer the primary direction for development of the industry. Investment of fixed capital has attained its bottleneck. In order for the industry to continue to increase its production, it has to adjust its industrial structure, 
improve the economic benefit and bring in more technology-oriented, science-oriented and highly competitive modern industries. Introduction of the new type of strategic industries is also likely to facilitate collaborative development of traffic and transportation, post and telecommunications and warehousing and modern finance. Thus, it makes sense that industrial value added is the most important influencing factor that affects collaborative development of the secondary industry and the tertiary industry.

Secondly, value added of the construction industry is the second influencing factor that has the largest influence on collaboration of the secondary industry and the tertiary industry, which is also understandable. The upstream and downstream industrial chain related with the construction industry is long, which involves development of multiple industries, such as, industry, financing, traffic and transportation and so on. Healthy development of the construction industry is able to stimulate development of the upstream and downstream industries related. On the contrary, problems or bottleneck existing in development of the construction industry may affect development of multiple upstream and downstream industries. Therefore, it is necessary to make a scientific planning and reasonable implementation on development of the construction industry so as to facilitate more healthy and sustainable development of the secondary industry and the tertiary industry in Chengdu.

Thirdly, development of the secondary industry and the tertiary industry ought to focus more on efficiency and effectiveness, and should not only pursue speed, but also strive for method. It has to adjust measures to local conditions and according to circumstances and lay particular emphasis with focus and in correct direction according to characteristics of all stages of the economic development. Development of economy should not blindly reply on investment of fixed capital, especially development of economy in Chengdu, but should, instead, rely more on modern scientific and innovative capacity and core competitiveness to set up facilities of software and hardware. Only in this way, can development of the secondary industry and the tertiary industry in Chengdu be more coordinated.

\section{Countermeasures and Suggestions}

According to the above conclusions and in combination with reality of resource environment in Chengdu, we put forward the following policies and suggestions in order to better promote collaborative development of the secondary industry and the tertiary industry in Chengdu.

\subsection{Reasonable Jointing in Planning of Cheng-Yu Economic Area}

In the past few years, the nation has paid more and more attention to development of economy in western China. Planning of Cheng-Yu economic area is a regional economic project that has been launched by the country in which Sichuan Province and Chongqing are deemed as the dragon of development to stimulate economic development of other western areas. Development of Cheng-Yu economic area planning has brought enormous opportunities for development of Sichuan Province, especially Chengdu City. Chengdu municipal government ought to hold on to the development opportunities, reasonably joint Cheng-Yu economic area planning and make Chengdu developed to a western financial center, advanced manufacturing industry cluster area and western airlines demonstration area. Chengdu should thoroughly digest and comprehend content of developmental planning of Cheng-Yu economic area, take advantage of the preferential policies of the nation and Sichuan Province, and, meanwhile, take more feasible measures to attract more investors to come to Chengdu for investment and establishing a business. In order to realize economic development of Chengdu, it is necessary for the industrial collaboration to build a better platform.

\subsection{Standard Development of Industry and Construction Industry}

It is found from the analysis that industry and construction industry have the most obvious influences upon the secondary industry and the tertiary industry in Chengdu. Upstream and downstream industrial chain of industry and construction industry is long and both of the two industries furnish a large number of mechanical equipment and fixed facilities for development of other industries. In the meantime, development of industry and construction industry also calls for support of relative industries. Development of industry and construction industry should have an overall and scientific planning, adjust measures to local conditions and according to circumstances, make full use of reality of resource environment so as to develop in a scientific and healthy way. Development of industry and construction industry should not only pursue speed, but should strive more on quality and efficiency. Development of industry and construction industry should reduce pollution and protect the environment. Simultaneously, development of industry and construction industry ought to depend on developmental project of Cheng-Yu economic area, vigorously develop the new type of strategic industries, cultivate new leading industry and pillar industry and enhance the core competitive force of the industry. 


\subsection{More Scientific Investment of Fixed Capital}

Investment of fixed capital has enormous promoting and driving effect on development of economy at certain time and place and within a certain area. However, when the economy is developed to a certain extent, the effect of investment of fixed capital will be diminished greatly. It has been discovered through an analysis of the influencing factors in industrial collaboration in Chengdu, investment of fixed capital at present has limited effect on collaboration of the secondary industry and the tertiary industry. Investment of fixed capital should be more scientific. We should make pertinent investment of fixed capital according to the periodical features of development of all industries. Investment of fixed capital ought to be made into those industries and regions that the market is unlikely to resolve. The industrial development at the current stage calls for more scientific and innovative competence and more human capital investment. Therefore, we ought to enter and drop out of the investment in a reasonable way according to different characteristics of development of all industries and furnish due support and guarantee for healthy development and sustainable development of the industries.

\section{References}

An, Husen. (2005). An Introduction to Regional Economics. Economic Science Press.

An, Shiyin. (2007). Relying on Coordination of the Three Industries to Promote Economic Development. Chinese Cadres Tribune, (12), 43-45.

Bian, Geya, Chen, Kangning, \& Huang, Li. (2010). Coordination degree analysis of water resource-industrial system in Hebei Province. Journal of Economics of Water Resource, (5).

Dong, Chun, \& Da, Jie. (2008). Study on Collaborative Development of the Three Industries in Sichuan Province. Reform of the Economic System, (6), 35-38.

Gong, Qinlin. (2004). On construction of industrial chain and urban and rural coordinating development. The Economist World, (3).

Herman Haken. (1983). Advanced Synergetics, translated by Guo, Zhian. Science Press.

Herman Haken. (1984). Introduction to Synergetics, translated by Xu, Xishen et al. Atomic Energy Press.

Huang, Wei, \& Wu, Jiapeng. (2010). A Study on the Compound Degree of Coordination between Educational Development and Equity in China on the basis of Synergetics. Journal of Changsha University of Science \& Technology (Social Science), (5).

Liu, Wei, \& Li, Shaorong. (2002). Industrial Structure and Economic Growth. China Industrial Economics, (5).

Liu, Wei. (1996). Study on Industrial Structure during the Industrialization. China Renmin University Press.

Wang, Jici. (2001). Innovative Spaces: Enterprise Clusters and Regional Development. Peking University Press.

Xiao, Xuxin, \& Luo, Gaoyuan. (2009). Grey Correlational Analysis on Structure of Inbound Tourism Industry of China. Resource Development \& Market, (4).

Yang, Jirui. (2003). On the Strategic Thinking for "the Mutual-operation of the Three Industries and Integration of Urban and Rural Economy". Rural Economy, (2).

Zhang, Aimei. (2008). Grey Dynamic Correlation Analysis of Forestry Industrial Structure in Jilin Province. Journal of Beijing Forestry University (Social Sciences), (7). 
Table 1. Evaluation indictor system in collaboration of the secondary industry and the tertiary industry in Chengdu

\begin{tabular}{|c|c|c|}
\hline $\begin{array}{l}\text { First class } \\
\text { indicator }\end{array}$ & Second class indicator & Explanation \\
\hline \multirow{21}{*}{ 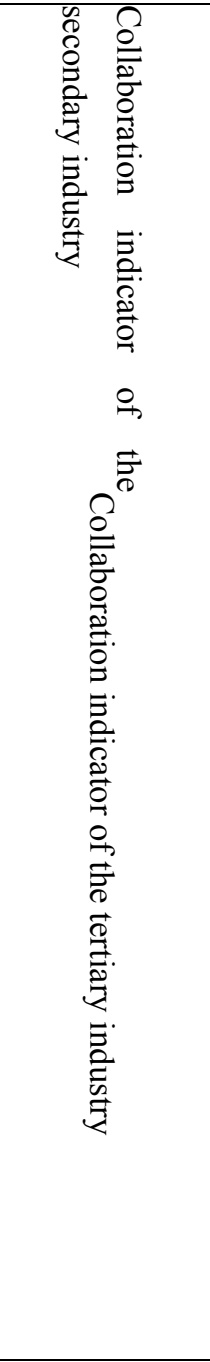 } & Contribution ratio of the secondary industry to GDP & \\
\hline & Ratio of output value of the secondary industry & \\
\hline & Value added of the secondary industry & \\
\hline & Industrial value added & \\
\hline & Investment of fixed capital in the secondary industry & \\
\hline & Value added of the construction industry & \\
\hline & Total output value of the construction industry & \\
\hline & Industrial investment & \\
\hline & Employment ratio of the secondary industry & \\
\hline & Value added of the tertiary industry & \\
\hline & Contribution ratio of the tertiary industry to GDP & \\
\hline & Investment of fixed capital in the tertiary industry & \\
\hline & Employment ratio of the tertiary industry & \\
\hline & Ratio of output value of the tertiary industry & \\
\hline & Investment in real estate & \\
\hline & Amount of sales in commodity housing & \multirow{4}{*}{$\begin{array}{l}\text { Totaling of finance and } \\
\text { insurance }\end{array}$} \\
\hline & Finance and insurance & \\
\hline & $\begin{array}{l}\text { Traffic Transportation, warehousing and posts and } \\
\text { telecommunications }\end{array}$ & \\
\hline & $\begin{array}{l}\text { Total appropriation expenditure of scientific and } \\
\text { technological activities }\end{array}$ & \\
\hline & Income of tourism & $\begin{array}{l}\text { Totaling of foreign and } \\
\text { domestic tourism }\end{array}$ \\
\hline & Social retail & \\
\hline
\end{tabular}


Table 2. Order parameter of the order degree of the system of the secondary industry and the tertiary industry in Chengdu

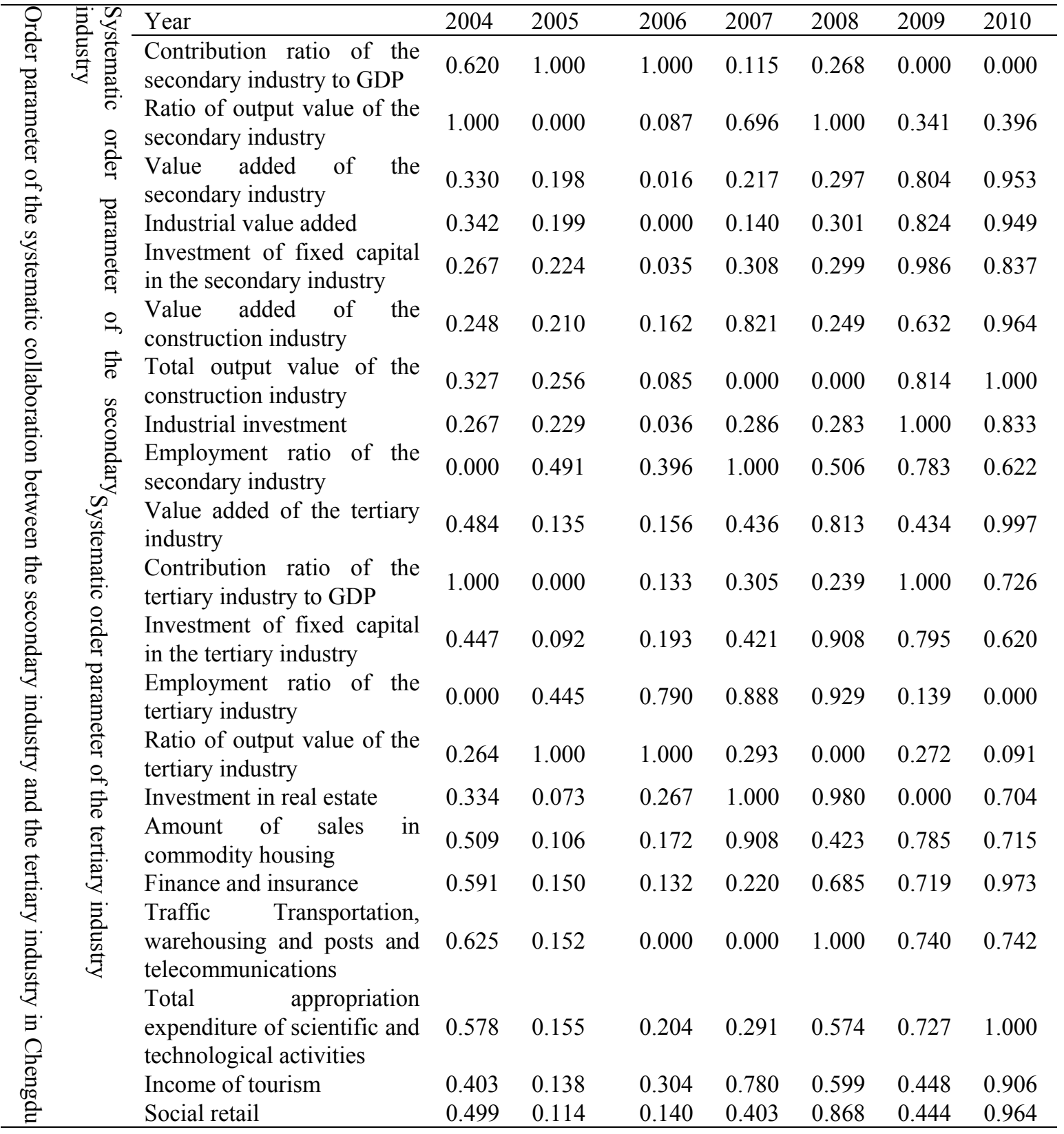


Table 3. Initial value

\begin{tabular}{|c|c|c|c|c|c|c|}
\hline Year & 2005 & 2006 & 2007 & 2008 & 2009 & 2010 \\
\hline Degree of collaboration & 1.000 & 1.609 & 0.160 & 0.365 & 0.588 & 1.547 \\
\hline Contribution ratio of the secondary industry to GDP & 1.000 & 0.664 & 0.149 & 0.295 & 0.766 & 1.029 \\
\hline Ratio of output value of the secondary industry & 1.000 & 0.337 & 0.118 & 0.698 & 0.172 & 0.089 \\
\hline Value added of the secondary industry & 1.000 & 0.640 & 0.130 & 0.419 & 0.743 & 1.583 \\
\hline Industrial value added & 1.000 & 0.666 & 0.180 & 0.423 & 0.788 & 1.572 \\
\hline Investment of fixed capital in the secondary industry & 1.000 & 0.662 & 0.075 & 0.455 & 1.235 & 1.326 \\
\hline Value added of the construction industry & 1.000 & 0.428 & 0.278 & 0.385 & 0.380 & 1.671 \\
\hline Total output value of the construction industry & 1.000 & 0.641 & 0.328 & 0.157 & 0.918 & 2.076 \\
\hline Industrial investment & 1.000 & 0.668 & 0.092 & 0.444 & 1.284 & 1.328 \\
\hline Employment ratio of the secondary industry & 1.000 & 0.360 & 2.583 & 4.144 & 4.656 & 3.735 \\
\hline Value added of the tertiary industry & 1.000 & 0.690 & 0.230 & 0.208 & 1.006 & 2.059 \\
\hline Contribution ratio of the tertiary industry to GDP & 1.000 & 0.549 & 0.302 & 0.607 & 1.157 & 1.389 \\
\hline Investment of fixed capital in the tertiary industry & 1.000 & 0.584 & 0.226 & 0.339 & 1.212 & 1.571 \\
\hline Employment ratio of the tertiary industry & 1.000 & 0.431 & 1.219 & 1.441 & 2.600 & 4.153 \\
\hline Ratio of output value of the tertiary industry & 1.000 & 0.394 & 0.413 & 1.221 & 0.865 & 1.269 \\
\hline Investment in real estate & 1.000 & 0.478 & 0.428 & 0.436 & 0.538 & 1.577 \\
\hline Amount of sales in commodity housing & 1.000 & 0.627 & 0.348 & 0.445 & 1.240 & 1.697 \\
\hline Finance and insurance & 1.000 & 0.746 & 0.523 & 0.018 & 1.309 & 2.112 \\
\hline $\begin{array}{l}\text { Traffic Transportation, warehousing and posts and } \\
\text { telecommunications }\end{array}$ & 1.000 & 0.925 & 0.816 & 0.555 & 1.334 & 1.908 \\
\hline $\begin{array}{l}\text { Total appropriation expenditure of scientific and } \\
\text { technological activities }\end{array}$ & 1.000 & 0.658 & 0.434 & 0.221 & 1.333 & 2.163 \\
\hline Income of tourism & 1.000 & 0.504 & 0.210 & 0.168 & 1.027 & 1.994 \\
\hline Social retail & 1.000 & 0.677 & 0.259 & 0.289 & 0.968 & 1.936 \\
\hline
\end{tabular}


Table 4. Difference value

\begin{tabular}{|c|c|c|c|c|c|c|}
\hline Year & 2005 & 2006 & 2007 & 2008 & 2009 & 2010 \\
\hline Degree of collaboration & 1 & 1.609 & 0.160 & 0.365 & 0.588 & 1.547 \\
\hline Contribution ratio of the secondary industry to GDP & 0 & 0.945 & 0.011 & 0.070 & 0.179 & 0.518 \\
\hline Ratio of output value of the secondary industry & 0 & 1.272 & 0.041 & 0.333 & 0.416 & 1.458 \\
\hline Value added of the secondary industry & 0 & 0.969 & 0.030 & 0.053 & 0.155 & 0.036 \\
\hline Industrial value added & 0 & 0.943 & 0.020 & 0.058 & 0.200 & 0.025 \\
\hline Investment of fixed capital in the secondary industry & 0 & 0.947 & 0.085 & 0.090 & 0.647 & 0.221 \\
\hline Value added of the construction industry & 0 & 1.180 & 0.119 & 0.020 & 0.208 & 0.125 \\
\hline Total output value of the construction industry & 0 & 0.968 & 0.168 & 0.208 & 0.330 & 0.529 \\
\hline Industrial investment & 0 & 0.941 & 0.068 & 0.079 & 0.696 & 0.219 \\
\hline Employment ratio of the secondary industry & 0 & 1.249 & 2.423 & 3.779 & 4.068 & 2.188 \\
\hline Value added of the tertiary industry & 0 & 0.919 & 0.070 & 0.158 & 0.418 & 0.513 \\
\hline Contribution ratio of the tertiary industry to GDP & 0 & 1.060 & 0.143 & 0.242 & 0.569 & 0.158 \\
\hline Investment of fixed capital in the tertiary industry & 0 & 1.025 & 0.067 & 0.026 & 0.624 & 0.025 \\
\hline Employment ratio of the tertiary industry & 0 & 1.177 & 1.059 & 1.076 & 2.012 & 2.607 \\
\hline Ratio of output value of the tertiary industry & 0 & 1.215 & 0.254 & 0.856 & 0.278 & 0.277 \\
\hline Investment in real estate & 0 & 1.131 & 0.268 & 0.071 & 0.050 & 0.030 \\
\hline Amount of sales in commodity housing & 0 & 0.982 & 0.188 & 0.080 & 0.652 & 0.150 \\
\hline Finance and insurance & 0 & 0.863 & 0.363 & 0.347 & 0.721 & 0.566 \\
\hline $\begin{array}{l}\text { Traffic Transportation, warehousing and posts and } \\
\text { telecommunications }\end{array}$ & 0 & 0.684 & 0.656 & 0.190 & 0.746 & 0.361 \\
\hline $\begin{array}{l}\text { Total appropriation expenditure of scientific and } \\
\text { technological activities }\end{array}$ & 0 & 0.951 & 0.274 & 0.144 & 0.745 & 0.617 \\
\hline Income of tourism & 0 & 1.105 & 0.050 & 0.198 & 0.439 & 0.447 \\
\hline Social retail & 0 & 0.932 & 0.099 & 0.076 & 0.380 & 0.389 \\
\hline
\end{tabular}


Table 5.

\begin{tabular}{|c|c|c|c|c|c|c|}
\hline Year & 2005 & 2006 & 2007 & 2008 & 2009 & 2010 \\
\hline Degree of collaboration & 1 & 1 & 1 & 1 & 1 & 1 \\
\hline Contribution ratio of the secondary industry to GDP & 1 & 0.683 & 0.995 & 0.967 & 0.919 & 0.797 \\
\hline Ratio of output value of the secondary industry & 1 & 0.615 & 0.980 & 0.859 & 0.830 & 0.583 \\
\hline Value added of the secondary industry & 1 & 0.677 & 0.985 & 0.974 & 0.929 & 0.982 \\
\hline Industrial value added & 1 & 0.683 & 0.990 & 0.973 & 0.910 & 0.988 \\
\hline Investment of fixed capital in the secondary industry & 1 & 0.682 & 0.960 & 0.958 & 0.759 & 0.902 \\
\hline Value added of the construction industry & 1 & 0.633 & 0.945 & 0.990 & 0.907 & 0.942 \\
\hline Total output value of the construction industry & 1 & 0.677 & 0.924 & 0.907 & 0.861 & 0.794 \\
\hline Industrial investment & 1 & 0.684 & 0.968 & 0.963 & 0.745 & 0.903 \\
\hline Employment ratio of the secondary industry & 1 & 0.620 & 0.456 & 0.350 & 0.333 & 0.482 \\
\hline Value added of the tertiary industry & 1 & 0.689 & 0.967 & 0.928 & 0.829 & 0.799 \\
\hline Contribution ratio of the tertiary industry to GDP & 1 & 0.657 & 0.935 & 0.894 & 0.781 & 0.928 \\
\hline Investment of fixed capital in the tertiary industry & 1 & 0.665 & 0.968 & 0.987 & 0.765 & 0.988 \\
\hline Employment ratio of the tertiary industry & 1 & 0.633 & 0.658 & 0.654 & 0.503 & 0.438 \\
\hline Ratio of output value of the tertiary industry & 1 & 0.626 & 0.889 & 0.704 & 0.880 & 0.880 \\
\hline Investment in real estate & 1 & 0.643 & 0.884 & 0.966 & 0.976 & 0.985 \\
\hline Amount of sales in commodity housing & 1 & 0.674 & 0.915 & 0.962 & 0.757 & 0.931 \\
\hline Finance and insurance & 1 & 0.702 & 0.849 & 0.854 & 0.738 & 0.782 \\
\hline $\begin{array}{l}\text { Traffic Transportation, warehousing and posts and } \\
\text { telecommunications }\end{array}$ & 1 & 0.748 & 0.756 & 0.915 & 0.732 & 0.849 \\
\hline $\begin{array}{l}\text { Total appropriation expenditure of scientific and } \\
\text { technological activities }\end{array}$ & 1 & 0.682 & 0.881 & 0.934 & 0.732 & 0.767 \\
\hline Income of tourism & 1 & 0.648 & 0.976 & 0.911 & 0.823 & 0.820 \\
\hline Social retail & 1 & 0.686 & 0.953 & 0.964 & 0.843 & 0.839 \\
\hline
\end{tabular}


Table 6. Ordering of the relevancy

\begin{tabular}{lll}
\hline Indicator & Relevancy & Ordering \\
\hline Industrial value added & 0.924788 & 1 \\
Value added of the construction industry & 0.924007 & 2 \\
Traffic Transportation, warehousing and posts and telecommunications & 0.908995 & 3 \\
Contribution ratio of the secondary industry to GDP & 0.90294 & 4 \\
Value added of the tertiary industry & 0.895616 & 5 \\
Investment in real estate & 0.893427 & 6 \\
Employment ratio of the secondary industry & 0.880865 & 7 \\
Amount of sales in commodity housing & 0.87703 & 8 \\
Investment of fixed capital in the tertiary industry & 0.876776 & 9 \\
Ratio of output value of the tertiary industry & 0.873436 & 10 \\
Industrial investment & 0.868634 & 11 \\
Contribution ratio of the tertiary industry to GDP & 0.865767 & 12 \\
Employment ratio of the tertiary industr & 0.862965 & 13 \\
Social retail & 0.860455 & 14 \\
Finance and insurance & 0.833302 & 15 \\
Ratio of output value of the secondary industry & 0.832644 & 16 \\
Income of tourism & 0.829836 & 17 \\
Total appropriation expenditure of scientific and technological activities & 0.820934 & 18 \\
Value added of the secondary industry & 0.811214 & 19 \\
Total output value of the construction industry & 0.647696 & 20 \\
Investment of fixed capital in the secondary industry & 0.540162 & 21 \\
\hline & & \\
\hline
\end{tabular}

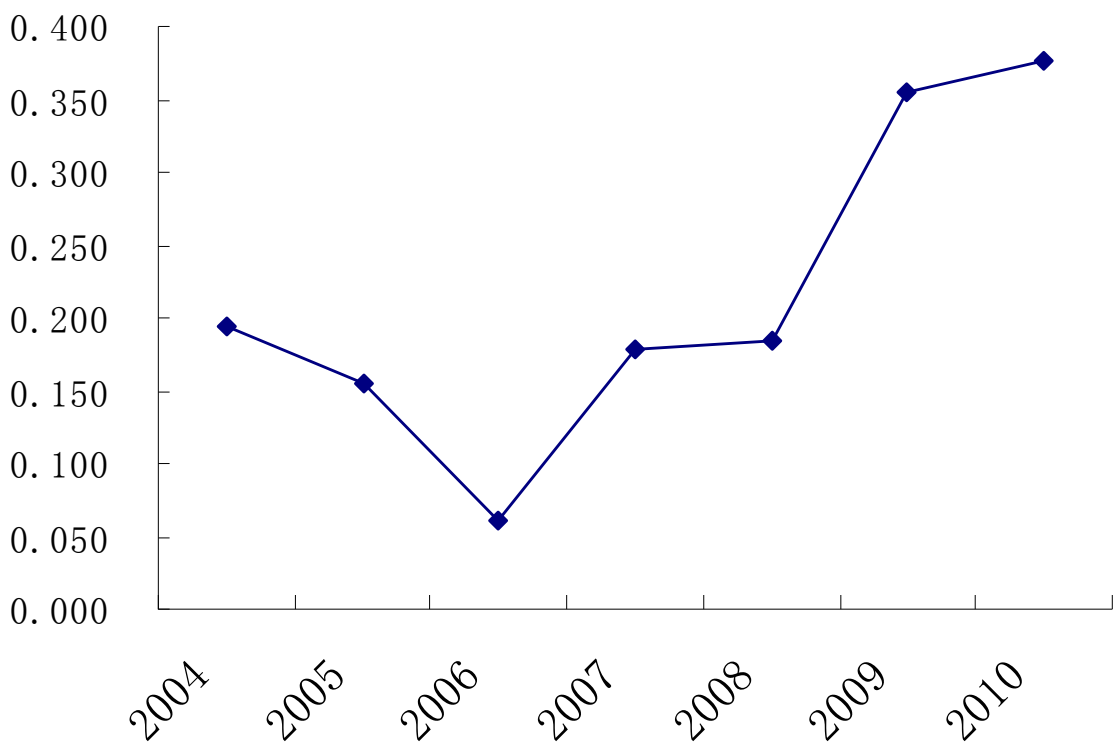

Figure 1. Line graph of the systematic order degree of the secondary industry 


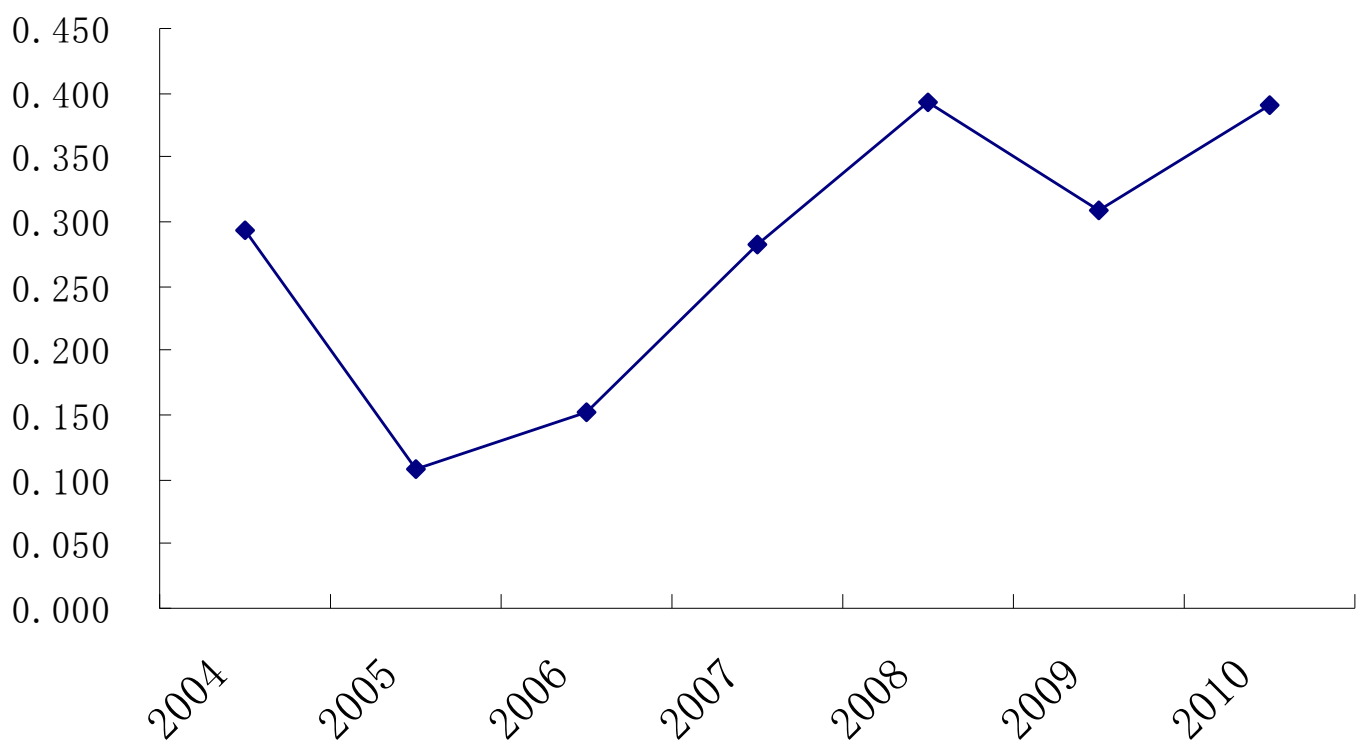

Figure 2. Line graph of the systematic order degree of the tertiary industry

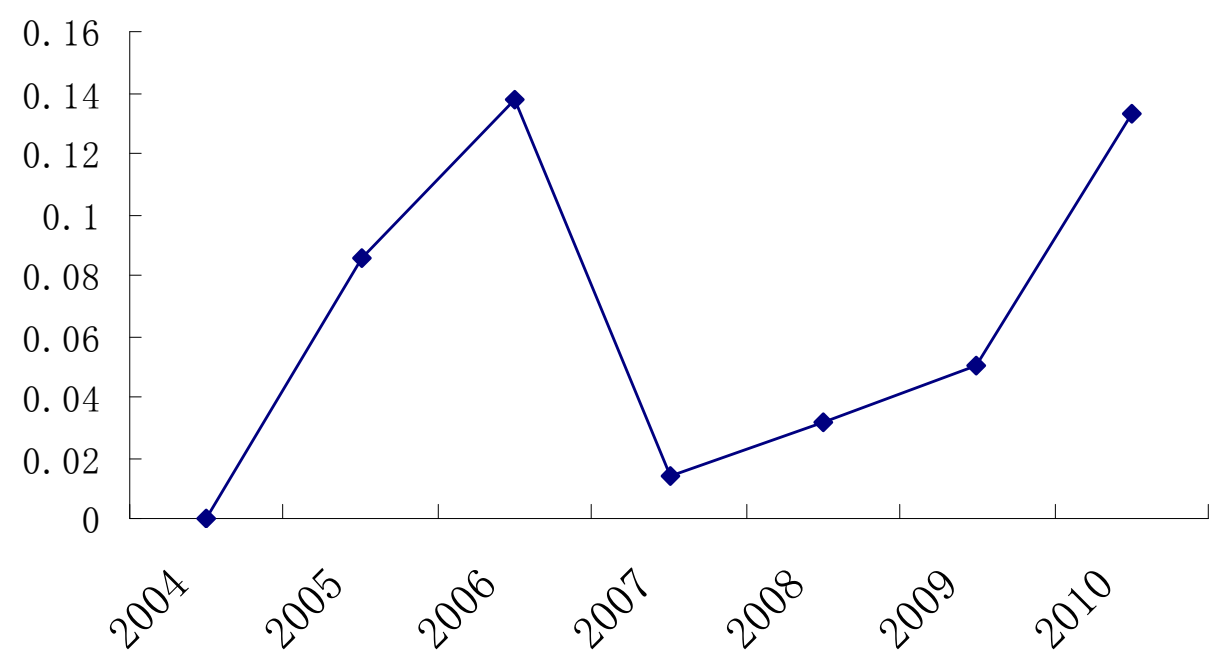

Figure 3. Systematic collaboration degree of the secondary industry and the tertiary industry 